\title{
IS ACTING ON EMERGING MARKETS ENVIRONMENT \\ A CHALLENGE OF THE UNKNOWN? THE ANSWER FROM COMPLEXITY THEORY PERSPECTIVE
}

\author{
Agnieszka DZIUBIŃSKA \\ University of Economics in Katowice, Department of Enterprise Management, 1 Maja 50, 40-287 Katowice, \\ Poland; agnieszka.dziubinska@ue.katowice.pl, ORCID: 0000-0003-4385-1123
}

Purpose: The contemporary environment imposes tensions, which result in growing unpredictability, on companies. This makes it difficult to rely on traditional forms of organization and strategies based on the rational decision-making model. The aim of the author's own research was to identify the ways of adaptation of enterprises to the conditions of emerging markets, which are defined as a business environment of high uncertainty.

Design/methodology/approach: A single case study was used in the research. The enterprise selected for the research is a good example of the studied phenomenon, which also made convenient access to data in longitudinal studies possible. The obtained results were confronted with the literature on the subject in the field of CAS.

Findings: The case of the enterprise selected for the study belongs to a group of independent SMEs that can compete against the largest players in the industry. The results of the study indicated that it was possible due to similar mechanisms existing on various levels of the analysis. These include making decisions based on the patterns derived from personal experience; high adaptability resulting from the required diversity, which, at the same time, makes effectiveness more important than efficiency; lack of a clear strategy, and instead the ability to deal with initial conditions and monitoring the emergence of patterns; openness to experimentation, and individual assessments and measures.

Research limitations/implications: The limitations of the obtained results may result from a limited test sample.

Originality/value: The theoretical perspective adopted in the research - CAS and the empirical dimension - emerging markets, constitute a relatively little explored alternative to research conducted in their mainstream. The obtained research results may be of interest to representatives of science and practice, especially with regard to the current crisis caused by the Covid-19 pandemic.

Keywords: unpredictability, emerging markets, CAS.

Category of the paper: Research paper. 


\section{Introduction}

The diverse business environment conditionings created by the global economic system have influence on the diversity of forms of business organisations and their strategies (Jones, 2019). For at least few decades, emerging markets have been an interesting and ambiguous strategic challenge on the competitive world map $^{1}$. One of the reasons for this is the fact that, together with the development of global economy, the relationships with entities on emerging markets have become common in virtually every industry (Ghemawat, and Jones, 2017). On the one hand, they create a potential for traditional sources of cost advantages, but also for very large, and therefore attractive, markets. On the other hand, however, these markets are associated with high uncertainty. The reason for that is the lack of institutions appropriate for mature markets, whose task is "to reduce uncertainty by establishing stable (yet not necessarily efficient) structures within human interactions" (North, 1990, p. 5). In general sense, institutions are "socially created constraints which give a structure to social interactions" (North, 1990, p.3). Taking this research perspective, Khanna and Palepu (2010, p. 6) defined the emerging market as a place where the buyer and the seller cannot do business easily. Such an approach towards emerging markets allows us to look at them more through the prism of properties they are characterised by than with regard to the geographical dimension with which they are most frequently identified. This perspective seems to be interesting from the point of view of crises and the accompanying uncertainty which the entities present on the so-called mature markets have experienced in the recent years, such as, for example, the consequences of Brexit or the latest events related to the Sars-Cov-2 pandemic.

In the literature on the subject, the belief that they are on a development path that brings them closer to the model corresponding to mature markets is a common denominator of the vast majority of results obtained from the studies on emerging markets. However, emerging markets may be looked at in another way. Although, so far, this aspect has been less explored than mainstream studies, the scale of opportunities effectively seized by enterprises that come from "peripheral regions" can no longer be considered marginal. The successes of enterprises from emerging markets achieved thanks to a diversity of forms and high dynamics of development have become an inspiration for the author's own studies.

The objective of the studies whose results are presented in this article, was to identify ways in which enterprises that operate in emerging markets conditions handle uncertainty. The publications that address the issue of surprising strategies and organisational forms of enterprises from emerging markets contain analyses conducted from the point of view of

\footnotetext{
${ }^{1}$ The term "emerging markets" itself is considered to have been popularised in the 1980s. Currently, such terms as emerging economies, emerging markets, middle income countries happen to be used interchangeably. "Emerging markets" replaced previously used terms such as "the second-world countries" or even "the thirdworld countries." These are countries of low income, high growth rate, which use liberalisation as their basic growth generator (Hoskisson et al., 2000).
} 
traditional ways of competing, and concern mainly the largest enterprises. The complexity theories (Rokita, and Dziubińska, 2016) create a new perspective within this scope, and the assumptions resulting from this appear particularly promising with regard to emerging markets. Therefore, this theoretical perspective has been adopted in the author's own studies.

The structure of the article is composed of the following parts. First, the idea of complex adaptive systems (CAS) and selected issues related to their dynamics were presented. Then, on this basis, the components of complexity in the actions of an enterprise from an emerging market purposefully selected for the studies were identified. The obtained results made it possible to attempt to determine the characteristics of enterprises that are of key significance within this scope, which were later confronted with the literature on the subject. The summary of the results obtained in this way in terms of the characteristics of enterprises that handle the challenges of the environment characterised by high uncertainty is the last part of the article.

\section{Organisation as CAS in the environment of emerging markets}

The issue of new forms and routines emerging from simple mechanisms as building blocks raised in the author's own studies falls within the area appropriate for the complexity theory (Holland, 1998; Gellman, 2002; Hazy, Backström, 2013). CAS constitute the basic unit of analysis in the complexity science. CAS are networks of interactions similar to neural networks between independent agents who are connected with one another by dynamic cooperation, e.g. in reaching common objectives, satisfying common needs or representing a common point of view. Hedlund (1994, p. 82) described similar structures as temporary groups of people and units. CAS are natural for social systems (e.g., Homans, 1950; Roy, 1954). The property of CAS is that they are able to learn, solve problems creatively and adapt quickly (Carly, and Hill, 2001' Carly, and Lee, 1998; Goodwin, 1994; Levy, 1992; Rokita, and Dziubińska, 2016).

There are a few different approaches towards defining CAS. One of them is the reference to constraints. Referring to what has already been mentioned in the introduction, these constraints may be identified with the rules in force on the market that regulate behavior of agents (Dziubińska, 2017). These "rules of the game" consist of formal rules (laws, regulations) and informal constraints (customs, norms, culture). On mature markets, properly functioning rules specify the possible behavior of agents. Therefore, a relatively low risk that consists in the fact that undertaken interactions between participants of the system will lead to foreseeable results, is a characteristic feature of mature markets. Accordingly, from this point of view, poor security of transactions, communication, partner transparency on emerging markets gives room for opportunistic behavior and increases uncertainty (Khanna, and Palepu, 2010, pp. 41-51). 
In a situation where agents are not bound by the rules, there are also no repetitive patterns, and foreseeable results cannot be expected. The behavior of the whole system is then characterized by randomness, or to put it differently, chaos. In the practice of social systems, chaos is always a temporary state. A practical example of such a state of the market can be a crisis resulting from the collapse of previously binding economic structures or time of deeper political and social transformation. Emerging from the state of chaos towards an orderly system, for example, by imposing draconian strict rules, or towards systems in which emergence plays a significant role.

Therefore, the third state of the system is also possible, in which the rules (e.g., by their less formal nature) limit the behavior of agents to a lesser extent than it is in orderly systems, whereas agents modify these rules as a result of interactions occurring during the time. Agents and system constraints - rules co-evolve.

Dooley (2006) describes CAS as aggregates of interacting agents who evolve according to three basic principles: the order emerges in the opposite way to the pre-defined one, the history of the system is irreversible, the future of the system is often unpredictable. Due to the randomness present in the system, and because of the fact that dynamics of complex systems may be highly sensitive to small disturbances (Lorenz, 1993), CAS correspond more to the metaphor of an organic ecosystem than to the metaphor of a machine. The change in CAS appears in unexpected places and is non-linear, and the history of the system is irreversible, i.e., a return to the initial conditions is not possible.

CAS create fundamentally different conditions for activities of the agents. In particular, one of the basic differences between a complex system and a complicated system is worth emphasizing. If a system can be described on the basis of its individual constituents, even if their number is huge, it is then complicated. If interactions between the constituents of the system and interactions between the system and environment are of such nature that the system as a whole cannot be fully understood by a simple analysis of its constituents, it is then complex (Cilliers, 1998). CAS are unique and extraordinary in their ability to adapt to changes of the environment in a quick and creative manner. CAS increase their ability to adapt to environmental problems or internal needs through diversification of their behavior and strategies (Holland, 1995; McKelvey, 2008). Such diversity, in view of complexity, is understood as an increase in internal complexity (number and level of interdependence, heterogeneousness of skills and points of view within CAS, number of CAS and tension) up to a level that is reached by competitors or above (level of necessary Ashby variety 1963). By increasing their complexity, which has already been mentioned above, CAS increase their ability to process data (Lewin, 1992), solve problems (Levy, 1992), learn (Carley, and Hill, 2001; Levy, 1992) and change creatively (Marion, 1999). These are the properties that seem to be desirable in the conditions of high uncertainty of the environment. 


\section{Methodology of the author's own studies and case study}

The research procedure has been subordinated to the assumptions of the qualitative approach that is aimed at building a theory (Eisenhadrt, 1989; Yin, 2009). To be more precise, a single-time case study was applied. With regard to its mode of operation, the company that has been selected for the study constitutes a very good example of the studied phenomenon. The company was able to achieve success in spite of lack of traditional sources of advantage. Moreover, cooperation with this company enabled the author to gain an exceptionally convenient access to data that are relatively difficult to obtain (Yin, 2009; Eisenhardt, and Graebner, 2007).

The company in its current form appeared on the Polish market in 2014, however, the history of its brand reaches the year 1933. Before 2014, the company had been located in Silesia, and after the second world war it operated as an industrial state-owned enterprise. In 1991, the company transformed into a Sole-shareholder Company of the State Treasury. In 1998, its shares were included in the National Investment Fund program. In 2004, the controlling interest was purchased by an Italian investor who incorporated the company as a branch to its international structure. In 2014, the company was taken over by a Polish entrepreneur who concentrated on the activity in the mining industry, in the field of control hydraulics. In 2018, company X was ranked, inter alia, among the Brilliants of Polish Economy (in Polish: Brylanty Polskiej Gospodarki). In 2019, the company was developing dynamically in the area of project execution. Company X (the name was encoded for the purposes of publication of the results) is located on the Polish market, but it also conducts international activity. The spatial extent of the study included three selected markets which the company operates on, i.e., Poland, China and Russia. The study was of longitudinal nature and encompassed the years 2014-2019.

The data came from a few sources: in-depth direct interviews and direct observation. The interviews (lasting from one to two hours) were conducted with employees with relevant knowledge at all organizational levels. The data were collected until saturation was reached, i.e., when subsequent information did not cause an increase in knowledge about the described phenomena. The collected data were subject to triangulation by cross-checking against annual reports, company's internal documents, statements published by company $\mathrm{X}$ and its partners (domestic and foreign). The data analysis was conducted using a constant comparative method to extract and refine categories from notes and documents. The data were coded by only one person which may constitute a certain constraint. However, the summarized data and initial results were reinterpreted by the respondents. In the last stage of the analysis, the obtained categories were confronted with a list of basic complexity ingredients in entrepreneurial activities according to the suggestion developed by McKelvey (2016). 


\section{Results of studies and their interpretation Company $X$ as CAS}

The industry of mining equipment manufacturers where company $\mathrm{X}$ operates is a typical example of a mature industry. One of the characteristic symptoms of this state is that after the wave of consolidations and acquisitions on the market, a very limited number of, mostly large, companies remained on the market. Their basic advantage is ability to provide holistic solutions within sets of devices. Furthermore, the companies have at their disposal traditional sources of advantages such as high level of concentration of capital and global reach. At this point it is worth noting the competitive situation created by the sector itself. On the one hand, for a long time, the economies of many countries have been indicating high demand for energy. On the other hand, the vision of limited natural resources and increasing pressure on the part of the natural environment result in the fact that specific ways of diverting from obtaining energy from fossil fuel combustion more and more frequently appear in political declarations of the most important state officials. These factors and the very dynamic economic growth, especially of the largest economies defined as emerging markets (including BRIC) made them become one of the most significant markets for the manufacturers of mining equipment. It is interesting that small and medium-sized European companies performed surprisingly well on these markets. Having at their disposal advanced technological solutions, they were able to compete successfully with global rivals. It should also be emphasized that very often competition with the largest companies required cooperation of many small, independent entities that were only able to provide the client with the whole complex of devices together.

The presented context makes it possible to outline strategic challenges faced by small and medium-sized companies competing internationally. From the point of view of the addressed issue, the basis for the success of these companies can be, in a synthetic manner, summarized in the following way: in the face of challenges that are impossible to predict in advance resulting from the unknown environment of emerging markets, and lack of efficient control over the whole project by independent entities, the companies had to deal with the emerging situation in an adaptive way, based on their abilities to learn and creative thinking. The case of company $\mathrm{X}$, deliberately selected for the studies, is among these companies. Unlike its partners, company $\mathrm{X}$ did not have distinctive technical key competences. As a small company, it also had at its disposal limited opportunities within the scope of expert management systems. The part of the project provided by company $\mathrm{X}$ constituted an element which was rather easy to obtain. However, company $\mathrm{X}$ could effectively exploit its resources thanks to the strengths such as relationship skills and experience in operations on both mature and emerging markets. These skills proved their worth in practice. As other studies suggest, the group of small and medium-sized, highly adapted companies is not homogeneous. In particular, the stronger the technical dimension of key competences, the lower the tendency to adapt to unique local conditionings compared to the most open cases of companies (Dziubińska, 2015). 
The detailed characteristics of company X, i.e., its strong embedding in interactions with its partners, relatively ambiguous boundaries resulting from various (formal and not formally confirmed) forms of cooperation, strong reliance on experience (frequently non-formalized) or a development path shaped depending on the emerging events, justify the conviction that this is an example of a company that represents the CAS metaphor. With regard to the constraints imposed by the objective of the article specified in the introduction, particular attention will be paid to the aspect of CAS, i.e., basic complexity ingredients in entrepreneurial activities of company X. The most important of them are presented in table 1.

Table 1.

Dynamics of development of company X as CAS

\begin{tabular}{|c|c|}
\hline $\begin{array}{l}\text { "Constituents" of } \\
\text { complexity }\end{array}$ & Examples from the practice of the enterprise \\
\hline Adaptive pressure & Declining sector; competition on the part of global enterprises \\
\hline Dissipative structure & $\begin{array}{l}\text { Solving tensions / problems in cooperation between companies providing various } \\
\text { technical parts of the system; supporting the development of activities on the foreign } \\
\text { emerging market of companies from mature markets }\end{array}$ \\
\hline $\begin{array}{l}\text { Regions of emergence } \\
\text { (between the first and } \\
\text { second critical value) }\end{array}$ & $\begin{array}{l}\text { Lack of strict rules / procedures; overlapping and unspecified strictly in advance scopes } \\
\text { of responsibility; limited formal tools supporting decision-making processes - key } \\
\text { interpretation in a given context }\end{array}$ \\
\hline $\begin{array}{l}\text { Tiny initiating events } \\
\text { (catalysts) }\end{array}$ & Ideas for development inspired by the events resulting from daily contacts \\
\hline Links & $\begin{array}{l}\text { Diversified character of the bond - strong bonds based on trust and translating to } \\
\text { efficiency in mutual actions and weaker bonds (lower frequency and familiarity) which } \\
\text { made it possible to open new development paths (industries, markets, products) in the } \\
\text { long run. }\end{array}$ \\
\hline Path dependence & $\begin{array}{l}\text { Experience, next to "tiny initiating events" as one of the key factors shaping the } \\
\text { trajectory of the company's development }\end{array}$ \\
\hline Constraints & $\begin{array}{l}\text { Values (constraints free from the context) and conditionings resulting from particular } \\
\text { projects (context-sensitive constraints) }\end{array}$ \\
\hline Co-evolution & $\begin{array}{l}\text { Modifications of the modes of operation, modifications of products under the influence } \\
\text { of experiences from foreign markets }\end{array}$ \\
\hline Non-linearity & $\begin{array}{l}\text { Exploitation of developed solutions in new circumstances (market environment, } \\
\text { projects, experiments in new industries) }\end{array}$ \\
\hline
\end{tabular}

Own work with the use of McKelvey (2016), pp. 55-56.

Self-organization was a crucial mechanism present in the actions of the companies cooperating with one another as well as inside company $\mathrm{X}$. When unforeseen problems occurred, the employees could enjoy great freedom in searching for solutions (freedom of decision and applied measures). Although, in general, the mechanism worked well, it also generated other problems, for example, connected with the fact that due to its small size company $\mathrm{X}$ had at its disposal a limited number of employees, which means that there were limits to its competences. It could also be noticed that long-term tensions in case of growing problems favored a decrease in internal motivation of employees.

Acknowledging the key role of interaction and indicated mechanisms leading to selforganization perhaps reveals the most significant difference between traditional global, companies and the group of small and medium-sized companies that compete with them and assume a specific configuration depending on a given project. It is related to the so-called 
context-sensitive constraints which are inseparably accompanied by CAS and fundamentally differ from systems that are subject to reduction (Juarrero, 1999) ${ }^{2}$. Context-sensitive constraints (linkages and catalysts) work as bottom-up constraints on the system through its own past experiences and environment. It justifies the statement that CAS cover the initial conditions which accompanied their establishment, and that their origin and trajectories limit future development and evolution. High sensitivity to initial conditions and historically conditioned dynamic processes is a property of CAS. Thanks to them, the systems are able to self-organize and develop on path-dependence basis. Prigogine even claimed that systems "carry their history on their backs" meaning that the internal structure reflects their history. This property of CAS has its consequences for the opportunity to get to know and understand such organizations as the example of company X (by a researcher or another participant of the competitive market game). This is because no explanation here is possible without taking into consideration the trajectory and context of company's development in which it is embedded. It is not possible to determine here to what extent (perhaps seemingly unordered for an external observer) structure and actions of company $\mathrm{X}$ are a result of experiences in cooperation within the framework of groups of companies being established (seemingly ad hoc), and to what extent of the origin and long-term activity on emerging markets. However, the fundamentals of the complexity theory make it possible to notice an interesting, different from the one represented by traditional enterprises, model of adaptation to operating in the environment of high unpredictability. What is more, the long-standing presence of company $\mathrm{X}$ on the market proves that it can be at least as effective as traditional forms and strategies of competition.

\section{Conclusions: selected adaptive characteristics of companies operating in the conditions of high uncertainty}

The conditionings of the environment, which correspond to complex systems, create operating conditions of an organization that are fundamentally different from the ones that are characteristic for the structured systems. One of the most significant challenges for business organizations in this respect is uncertainty. The use of the CAS metaphor in the interpreting the results of the author's own studies has made it possible to distinguish a few characteristics of enterprises that have the ability to handle uncertainty in a different way than traditional enterprises.

\footnotetext{
${ }^{2}$ First order context-dependent constraints such as non-linear interactions, positive feedback and catalysts make units strongly co-dependent through the change of their marginal probabilities (probabilities of particular elements differ due to the fact that they occur in specific relationships).
} 
The conditions of high uncertainty do not make it possible to determine precise objectives in the long term, and to draw up a strategy that would specify detailed steps which are supposed to properly close the gap between the current state and the ideal future one (Komańda, 2011). The theory on the subject of CAS made it possible to notice an interesting alternative in the modes of actions of cooperating independent companies which company $\mathrm{X}$ belonged to. The companies did not operate within the framework of one stable structure. Instead, they organized themselves around a common objective which was prompt project execution and handled the emerging circumstances "on an ongoing basis" as well as the experience models emerging on this basis. Those patterns emerging from experiences which were positively assessed were maintained, while those ones which could have negatively influenced the results were disrupted. Especially in the latter case capturing signals quickly constituted a key ability. The mechanisms occurred on the level of the group of cooperating companies as well as within company X. Additionally, it should be emphasized that all the projects and results obtained within their framework in company X were assessed individually. In case of certain activities, high risk or low economic advantages was accepted at the price of gaining valuable experience. These are practical examples which can illustrate the thesis that Holling (1976) formulated about "optimization of failure costs", i.e., the system experiencing small periodic "minifailures" that do not threaten the survival (identity) of the system since they prevent the evolution of inflexibility. With regard to business activity, it should be emphasized that high adaptiveness based on creativity and learning means that efficiency is frequently achieved at the price of lower effectiveness. In other words, adaptability is possible thanks to a certain scope of lack of effectiveness.

Other significant issues that require attention are leadership and decision making. Unpredictability creates circumstances which make it impossible to make decisions based on assumptions resulting from a rational model of decision-making processes (Courtney, Kirkland, and Viguerie, 1997; Jędralska, 2010). In return, such companies as the case of company X, rely on models created through the accumulation of practical experience which are constantly confronted with emerging events. In such cases, the greater the diversity, the greater the ability to generate an appropriate response (McKelvey, and Boisot, 2010). The diversity of experience is also valuable on the level of the teams created, since uncertainty results in the fact that managing an organization on the basis of predetermined rules has its constraints. Tn alternative, confirmed by the practice of company $\mathrm{X}$, is to create a team which, thanks to self-organization, is able to cope with solving problems on its own. 


\section{Summary and directions of further studies}

The article addresses the issue of how to adapt companies in conditions of uncertainty. In the author's own studies, the environment of emerging markets has become their empirical expression. The CAS theory was used as a theoretical context for the considerations. This is a perspective which makes it possible to open a new direction of studies in the field of organization theory and strategic management. These two contexts of studies made it possible to attempt to identify the adaptive properties of an organization from the perspective which was not sufficiently explored in the mainstream studies. The presented results of the studies are a step towards a better categorization of terms that help to describe the effective actions of an organization in the conditions defined as unknown. This seems to be significant as traditional literature may not provide a sufficiently satisfactory basis for making decisions, and as a result, actions. The presented conclusions are a part of broader studies on the adaptation of an organization and seem to confirm the attractiveness of the open research path. This conviction is reinforced by the noticeable results of recent events which have shaped the economic reality of enterprises.

\section{References}

1. Ashby, R. (1963). Wstęp do cybernetyki. Warszawa: PWN.

2. Carley, K., and Hill, V. (2001). Structural change and learning within organizations. In: A. Lomi and E.R. Larsen (Eds.), Dynamics of organizational societies (pp. 63-92). Cambridge: AAAI/MIT Press.

3. Carley, K., and Lee, J.S. (1998). Dynamic organizations: Organizational adaptation in a changing environment. Advances in Strategic Management: A Research Annual, 15, pp-pp. 269-297.

4. Cilliers, P. (1998). Complexity and postmodernism: Understanding complex systems. London: Routledge.

5. Courtney, H., Kirkland, J., and Viguerie, P. (1997). Strategy Under Uncertainty. Harvard Business Review, 75(6), Nov.-Dec., pp. 67-79.

6. Dooley, K.J. (1996). Complex adaptive systems: A nominal definition. The chaos network, 8(1), pp. 2-3.

7. Dziubińska, A. (2015). An evolutionary approach to understanding adjustment of MNCs in a complex environment. Problemy Zarzadzania, 13/1(2), pp. 183-199.

8. Dziubińska, A. (2017). Innowacja instytucjonalna w warunkach transformacji otoczenia. Studia i Materiaty, 2/2017(24), cz. 1, pp. 48-59. 
9. Eisenhardt, K.M. (1989). Building theories from case study research. Academy of Management Review, 14(4), pp. 532-550.

10. Eisenhardt, K.M., and Graebner, M.E. (2007). Theory building from cases: opportunities and challenges. Academy of Management Journal, 50(1), pp. 25-32.

11. Gell-Mann, M. (2002). What is complexity. In: A.Q. Curzio and M. Fortis (Eds.), Complexity and Industrial Clusters: Dynamics and Models in Theory and Practice (pp. 13-24). Heidelberg: Physica-Verlag.

12. Ghemawat, P., and Jones, G. (2017). Globalization in Historical Perspective. In: P. Ghemawat (Ed.), The Laws of Globalization and Business Applications (pp. 56-81). Cambridge: Cambridge University Press.

13. Goodwin, B. (1994). How the leopard changed its spots: The evolution of complexity. New York: Charles Scribner's Sons.

14. Hazy, J.K. and Backström, T. (2013). Human Interaction Dynamics (HID): Foundations, definitions, and directions. Emergence: Complexity \& Organization, 15(4), pp. 91-124.

15. Hedlund, G. (1994). A model of knowledge management and the N-form corporation. Strategic Management Journal, 15(Special Issue), pp. 73-90.

16. Holland, J.H. (1995). Hidden order. Reading: Addison-Wesley Publishing Company.

17. Holland, J.H. (1998). Emergence: From Chaos To Order. Addison-Wesley.

18. Holling, C.S. (1976). Resilience and stability of ecosystems. In: E. Jantsch, and C.H. Waddington (Eds.), Evolution and Consciousness: Human Systems in Transition (pp. 73-92). Reading: Addison-Wesley.

19. Homans, G.C. (1950). The human group. New York: Harcourt, Brace and World.

20. Hoskisson, R.E., Eden L., Lau, C.M., and Wright, M. (2000). Strategy in Emerging Economies. Academy of Management Journal, 43, pp. 249-266.

21. Jędralska, K. (2010). Kontekst niepewności w procesie zarzadzania strategicznego. In: K. Jędralska (Ed.), Zarządzanie niepewnościa (pp. 9-28). Katowice: Wydawnictwo UE.

22. Jones, G. (2019) International Business and Emerging Markets in Historical Perspective. In: R. Grosse and K.E. Meyer (Eds.), The Oxford Handbook of Management in Emerging Markets (pp. 55-76). Oxford: Oxford University Press.

23. Juarrero, A. (1999). Dynamics in action: intentional behavior as a complex system. MIT Press Cambridge.

24. Khanna, T., and Palepu, K.G. (2010). Winning in Emerging Markets: A Road Map for Strategy and Execution. Boston: Harvard Business Press.

25. Komańda, M. (2011). Między wiedzą a niewiedzą: droga ku przewadze organizacyjnej. In: K. Hajduk (Ed.), Sustainability odpowiedzia na kryzys ekonomiczny. Nowe koncepcje przedsiębiorstwa przyszłości (pp. 258-263). Warszawa: Instytut Organizacji i Zarządzania w Przemyśle ORGMASZ.

26. Levy, S. (1992). Artificial life: The quest for new creation. New York: Random House.

27. Lorenz, E. (1993). The essence of chaos. Seattle: University of Washington Press. 
28. Marion, R. (1999). The edge of organization: Chaos and complexity theories of formal social organizations. Newbury Park: Sage.

29. Mc Kelvey, B., and Boisot, M. (2010). Redefining strategic foresight" "fast" and "far" sight via complexity science. In: L.A. Costanzo, and R.B. MacKay (Eds.), Handbook of Research on Strteagy and Foresight (pp. 15-47). Cheltenham/Northampton: Edward Elgar.

30. McKelvey, B. (2008). Emergent strategy via Complexity Leadership: Using complexity science and adaptive tension to build distributed intelligence. In: M. Uhl-Bien and R. Marion (Eds.), Complexity and leadership volume I: Conceptual foundations (pp. 225-267). Charlotte: Information Age Publishing.

31. McKelvey, B. (2016) Complexity Ingredients Required For Entrepreneurial Success. Entrepreneurship Research Journal Entrepreneurship Research Journal, 6(1), pp. 53-73.

32. North, D.C. (1990). Institutions, Institutional Change and Economic Performance. Cambridge: Cambridge University Press.

33. Rokita, J., and Dziubińska, A. (2016). Systemy złożone w zarządzaniu. Katowice: Wydawnictwo Uniwersytetu Ekonomicznego.

34. Roy, D. (1954). Efficiency and 'the fix': Informal intergroup relations in a piecework machine shop. American Journal of Sociology, 60, pp. 255-266.

35. Yin, R.K. (2009). Case studies: design and methods. Thousand Oaks: Sage Publications. 